\title{
El tranvía de San Cristóbal y la urbanización del suroriente bogotano, 1900-1940
}

\section{The Tramcar of San Cristóbal and the Urbanization of the Southeastern Bogotá, 1900-1940}

\author{
José Alejandro Cifuentes Sarmiento \\ Historiador de la Pontificia Universidad Javeriana \\ Candidato a Magíster en Historia de la Universidad Nacional de Colombia \\ Profesor del Departamento de Historia, Pontificia Universidad Javeriana, Colombia \\ https://orcid.org/0000-0002-4645-1937 \\ jose-cifuentes@javeriana.edu.co \\ Fecha de recepción: 30 de marzo del 2018 \\ Fecha de aceptación: 4 de mayo del 2018 \\ Disponible en línea: 27 de junio del 2018
}

Sugerencia de citación: Cifuentes Sarmiento, J. A. (2018). El tranvía de San Cristóbal y la urbanización del suroriente bogotano, 1900-1940. tiempo\&economía, 5(2), 135-153, doi: http://dx.doi.org/10.21789/24222704.1342

\section{RESUMEN}

El objetivo del presente artículo es estudiar la relación entre el proceso de urbanización del suroriente bogotano, la zona conocida como San Cristóbal, y el tranvía durante las primeras décadas del siglo XX. En la década de 1920 la zona de San Cristóbal era ya un importante núcleo de barrios para obreros. Adquirió tal importancia que fue uno de los puntos centrales de urbanización en el proceso de crecimiento de Bogotá. Aunque desde la década de 1890 existía un proyecto de construcción de un tranvía, sólo hasta 1917 operó el tranvía. La urbanización de San Cristóbal no esperó al tranvía, pero en el momento en que fueron conformándose los nuevos barrios del sector, este medio de transporte se convirtió en un servicio urbano de suma importancia tanto para los habitantes del sector como para los actores que buscaron promover el desarrollo de la zona. 
Palabras clave: Bogotá, transporte, historia del transporte, tranvía, historia urbana, historia económica

Códigos JEL: N76, N96, R42

\section{ABSTRACT}

The objective of this paper is to study the relationship between the process of urbanization of the southeast of Bogotá, the area known as San Cristóbal, and the tramcar during the first decades of the 20th century. The area of San Cristóbal was already in the 1920s a nucleus of neighborhoods for workers. It acquired such importance that it was one of the central urbanization areas in Bogota's growth process. Although since the 1890s there was a construction project for a tramcar, it was only until 1917 that the tramcar was operated. The urbanization of San Cristóbal, therefore, did not wait for the tramca, but at the time when the new neighborhoods of the sector were being formed, this means of transport became an urban service of great importance both for the inhabitants of the sector and for the actors that seek to promote the development of the area.

Keywords: transportation, transport history, tranmcar, urban history, economic history

JEL Codes: N76, N96, R42 


\section{Introducción}

El tranvía es uno de esos hitos del proceso de modernización de Bogotá que con el tiempo ha ido cobrando un mayor interés para los investigadores. Historiadores, urbanistas, economistas, entre otros, se han dedicado a estudiar la historia del tranvía de Bogotá y su impacto en la vida de la capital colombiana. Las investigaciones sobre el tranvía se han concentrado en la trayectoria histórica, las características y funcionamiento de la empresa del tranvía, tal es el caso de trabajos como Historia del tranvía en Bogotá (Contreras y Vélez, 1985), Vida pasión y muerte del tranvía en Bogotá (Jaramillo y Parias, 1995), Economía y transporte urbano en Bogotá (Esquivel, 1997) y Empresas públicas de transporte en Bogotá: siglo XX (Núñez y Rodríguez, 2003). En algunas otras investigaciones como La ciudad de los elegidos (Suárez, 2006), Santa Fe y Bogotá: Evolución histórica y servicios públicos (Vargas y Zambrano, 1988), El tránsito a la ciudad moderna 1920-1950 (Del Castillo, 2003), El tranvía municipal de Bogotá. Desarrollo y transición al sistema de buses municipal 1884-1951 (Baquero, 2009) y La ciudad del tranvía 1880-1820 (Montezuma, 2008), el análisis gira en torno a la relación de este sistema de transporte con las transformaciones urbanas que se presentaron en la Bogotá de la primera mitad del siglo xx.

De cara a la historia del tranvía, los trabajos citados han analizado los procesos de conformación de la empresa privada, de municipalización, de extensión de las redes y funcionamiento del sistema hasta su desaparición a principios de la década de 1950. En cuanto la relación entre este sistema de transporte y el desarrollo urbano de Bogotá, las investigaciones referidas han resaltado el impacto y el rol del tranvía en la expansión de Bogotá hacia el norte, y sobre todo la relación del tranvía con el desarrollo de la zona de Chapinero y la urbanización del norte.

No obstante, poco se ha dicho al respecto de la influencia del tranvía en el desarrollo urbano del sur de Bogotá durante la primera mitad del siglo xx. El funcionamiento del tranvía en el sur de la ciudad cobra mayor importancia si tenemos en cuenta que el primer proceso de ensanche de la ciudad fue lineal, en un eje de norte a sur a la sombra de los cerros orientales, entre Chapinero y San Cristóbal (Del Castillo, 2003, p. 82). San Cristóbal fue entonces un foco clave en el proceso de modernización de la capital, por lo que el análisis del tranvía en esta zona adquiere mayor importancia. Y esto si tomamos en consideración el hecho de que la urbanización en San Cristóbal tuvo un carácter distinto a la de Chapinero, pues allí surgieron, desde 1910, barrios para obreros, ${ }^{1}$ es decir, barrios destinados a población trabajadora.

La primera extensión del tranvía hacia el sur de la ciudad data de la década de 1890, cuando la empresa privada, controlada por capital norteamericano, tendió sus rieles entre la plaza de Bolívar y la plaza de Las Cruces (Contreras y Vélez, 1985), barrio al extremo sur de la capital surgido a mediados del siglo xIx (Mejía, 2000, p. 321). Pero si bien para principios del siglo xx el perímetro urbano de la ciudad se extendía por el sur hasta la calle $1^{\circ}$, límite sur del barrio Las

1 La palabra "obrero" en la Bogotá de principios de siglo XX designaba una gama de trabajadores manuales amplia, y no necesariamente se circunscribe al obrero industrial, como lo demuestran fuentes del periodo. Por ejemplo, en diversos números del Registro Municipal, donde en referencia al funcionamiento de las empresas municipales, los barrenderos, los operarios del tranvía y los trabajadores de los talleres de este, los cuidadores del cementerio municipal, entre otros, son designados como obreros, en contraposición a los administradores de estas empresas. Por otro lado, en periódicos autoproclamados obreros durante el mismo periodo, como El Ravachol, La Unión Obrera o El Socialista, aparece la misma tendencia: el obrero es el trabajador manual, por lo general, contratado por medio de salario, o incluso pequeños artesanos.

tiempo\&economía

Vol. 5 N. 2 - Julio - Diciembre del 2018 
Cruces, los terrenos ubicados entre esta calle y el río Fucha, pertenecientes al entonces municipio de Bogotá, comenzaron a transformase. Para la década de 1910 las haciendas del sector comenzaron a ser subdivididas y loteadas para darle paso a nuevos barrios como Villa Javier o el $1^{\circ}$ de Mayo. Las autoridades municipales, que para aquel momento ya controlaban la empresa, decidieron llevar el tranvía hasta San Cristóbal en 1917. Finalmente este sistema de transporte cruzó el río Fucha hacia el sur, y llegó hasta el barrio 20 de Julio, en la década de 1930.

En este estudio buscamos establecer la relación entre el tranvía de San Cristóbal y la urbanización del suroriente bogotano a principios del siglo xx. No pretendemos describir una relación causal, lineal, entre uno y otro, pues es simplista y falaz afirmar que la construcción de nuevos barrios en San Cristóbal se debe sólo a la línea del tranvía. De hecho, lo que nos muestran las fuentes es que la llegada del tranvía municipal a las tierras aledañas al río Fucha se debió al proceso mismo de urbanización de San Cristóbal. Lo que aquí se quiere es comprender la relación compleja entre el tranvía y el crecimiento urbano en el suroriente bogotano.

\section{El inicio de la urbanización de San Cristóbal y la primera línea de tranvía}

Cuando hablamos de San Cristóbal pensamos en la actual localidad -subdivisión administrativa del Distrito Capital colombiano- del suroriente bogotano. Pero en este trabajo, cuando hablamos de San Cristóbal nos referimos a una zona histórica de Bogotá que se ubicaba, de norte a sur, entre los límites al sur de la ciudad, marcados por la calle $1^{\text {a }}$ desde el siglo xIx, y el río Fucha, y de oriente a occidente, entre el camino a Ubaque y el camino a Tunjuelo (actual avenida (aracas), tal como se puede ver en el Plano 1. Desde tiempos coloniales esta fue una zona rural dominada por haciendas de comunidades religiosas y notables de la ciudad. Esta zona también era sede de algunas actividades productivas como fabricación artesanal de teja y ladrillo (chircales), molienda de harina y producción de pólvora. Esta situación se explica por los recursos allí disponibles: el río Fucha era una buena fuente de energía para los molinos, y en las laderas de los cerros se encontraban yacimientos de arcilla y fuentes calóricas para los hornos de cocción (Martínez, 1983, pp. 64-65).

Durante la segunda mitad del siglo xIX, al mismo tiempo que la producción de ladrillo aumentaba, algunos ciudadanos comenzaron a pensar seriamente en urbanizar San Cristóbal como un suburbio semejante a Chapinero. Estas ideas darían forma al primer barrio del sector, llamado también San Cristóbal. Uno de los primeros personajes que vio una oportunidad de empresa incentivando la urbanización de San Cristóbal fue Fortunato Pereira Gamba. Este personaje, nacido en Bogotá en 1866, fue un ingeniero que intentó varias empresas mineras, se dedicó al comercio y que incluso trabajó en la ferrería de la Pradera. Pereira Gamba vivió entre 1895 y 1904 en San Cristóbal. Compró una hacienda en el suroriente bogotano, y nos dice un biógrafo, allí se dedicó a la plantación de eucalipto (Buendía, 1974, pp. 270-288). ${ }^{2}$

Pero es el mismo Pereira Gamba quien nos relata con más detalle su vida en el suroriente capitalino. El ingeniero, que reclama haber sido uno de los primeros impulsores del barrio San Cristóbal, dice que llegó a la zona con el fin de "emprender en la industria chircalera". Compró la finca El Chorro, propiedad en la cual se dedicó a la fabricación de ladrillo a la extracción de

2 Pereira Gamba fue de uno de los principales defensores del uso del árbol de eucalipto para la recuperación de las hoyas hidrográficas y la reforestación de los cerros de Bogotá (Pereira, 1899, pp. 217-223). 
cal y carbón. Luego pensó en estimular el desarrollo urbano, proveyendo tierras para iniciar la construcción de un nuevo barrio en el sector. El problema, según el mismo Pereira, es que supuso que "bastaba ofrecer tierras para fundar nuevos barrios y materiales de construcción", y en realidad fueron "pocas las gentes [que] se apresuraban al Ilamamiento". El proyecto urbanizador entonces no tuvo el vigor que Pereira esperaba. Por lo que se puede ver en las notas autobiográficas de Pereira, este esperaba que su barrio fuera un barrio de viviendas de recreo, alejadas de las dinámicas de la ciudad. El mismo Pereira nos dice que llevó su vida en San Cristóbal era "campestre social", jugaba al tiro al blanco con sus amigos y practicaba la cacería (Pereira, 1919, pp. 104-114). En otras, palabras, Pereira proyectaba la urbanización en San Cristóbal como una zona para sectores sociales acomodados, como ocurría con Chapinero, al otro lado de la ciudad.

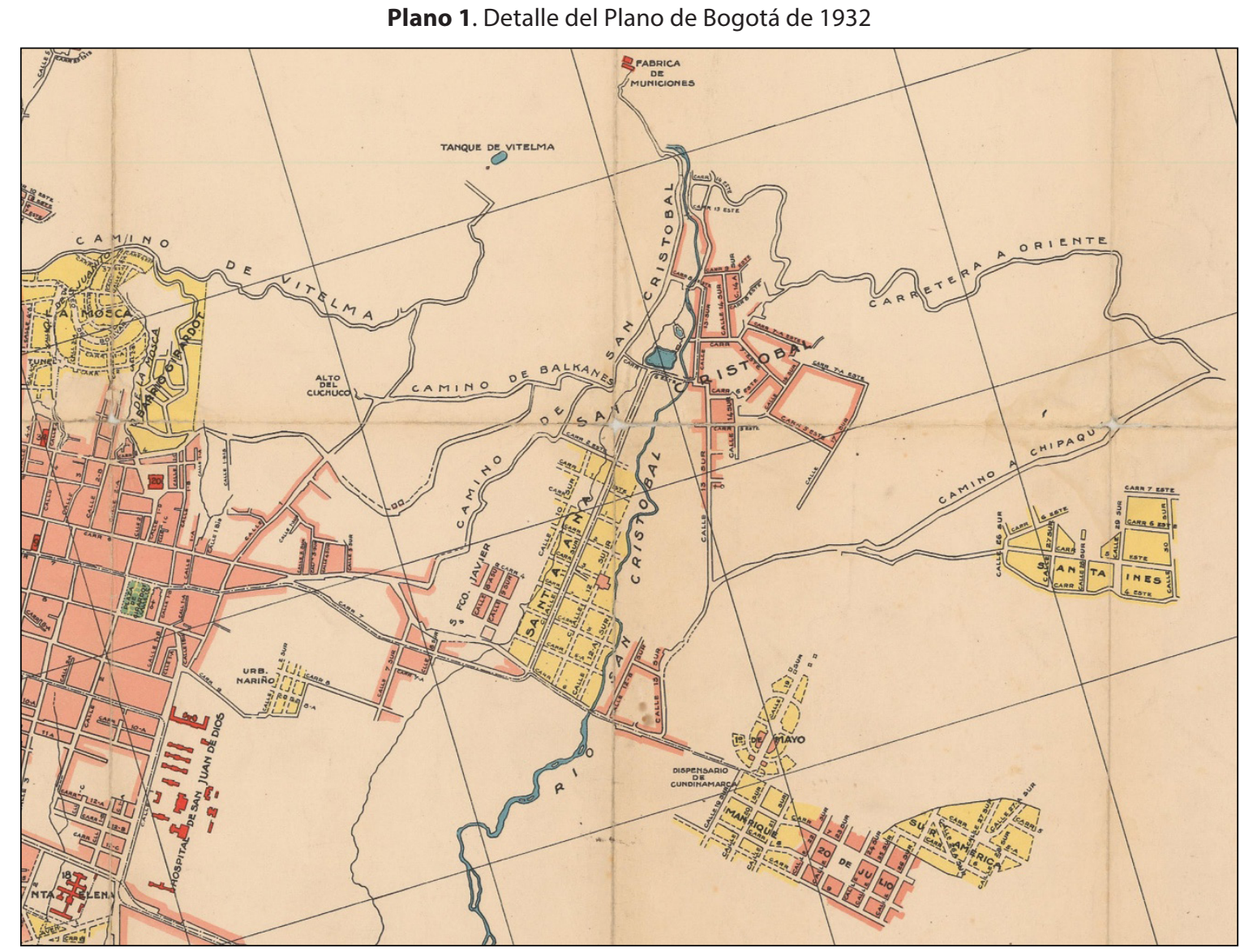

Se detalla el sector de San Cristóbal en el plano de la ciudad de 1932. Aparecen en rojo los barrios construidos o en construcción: San Cristóbal, Villa Javier, 20 de Julio y $1^{\circ}$ de Mayo. En amarillo los barrios planificados: Santa Inés, Santa Ana y Suramérica. El sector es atravesado de oriente a occidente por el río Fucha, también conocido como río San Cristóbal. Por el oriente la zona estaba delimitada por la Carretera a Oriente, el viejo camino a Ubaque.

Fuente: Cuéllar y Mejía (2007, p. 83)

Con el fin de estimular el desarrollo económico y urbano de San Cristóbal, Pereira intentó comunicar esta zona con la plaza de Las Cruces por medio de un tranvía. Para ello constituyó en 1897, junto a Máximo González, una sociedad que se encargaría de la construcción de la línea y de ponerla en funcionamiento. El proyecto, que no llegó a materializarse, fue expuesto en 
un folleto publicado en 1898. Aunque el objetivo principal de este folleto era mostrar la pertinencia de una nueva línea de tranvía hacia el suroriente para atraer inversionistas, también buscaba presentar a San Cristóbal como una zona importante en el futuro inmediato de la capital, y que sus terrenos eran prometedores para la inversión. En últimas, Pereira y González justificaban la necesidad de su tranvía argumentando que este medio de transporte iba a dar el empujón decisivo para que un sector económico y urbanísticamente promisorio, como lo era San Cristóbal, iniciara el camino del progreso.

Los empresarios nos dicen que basta comparar el grado de desarrollo que se había alcanzado en Chapinero frente a la situación de abandono que vivía San Cristóbal, para comprender que el atraso no podía sino atribuirse "á la falta de comunicaciones fáciles". Y no es que San Cristóbal no contara con características que hicieran posible el desarrollo de la zona, por lo que Pereira y González exponían algunas de las bondades del sur de la ciudad. En primer lugar, señalaban que la zona, ya poblada, comenzaba a experimentar una "creciente afluencia de población". Lo anterior produjo una situación en la que "diferentes propietarios venden lotes de terreno en las cercanías del río á precios de entre \$1-50 á \$ 0-50 el metro cuadrado". Ahora, la ubicación de San Cristóbal es comparativamente estratégica, ya que la "distancia del centro de la ciudad al río [...] es solamente la mitad de la que hay á Chapinero", y eso sin contar que la "región de San Cristóbal tiene ventajosa provisión de aguas". La disponibilidad de agua potable se sumaba al hecho de que el suroriente contaba con un "abundante y seguro mercado de víveres, puesto que por el camino de Ubaque transita buena mayoría de los que abastecen la ciudad", haciendo de San Cristóbal un lugar ideal para la vivienda. Por estos motivos, se vaticinaba que el progreso de la zona era "seguro y su desarrollo será, sin duda, más rápido que la región del norte" (González y Pereira, 1898, pp. 4-5).

Los autores le atribuían una gran importancia a la industria y a la minería en San Cristóbal, sobre todo de cara al futuro del sector. Esta, además, era la razón que justificaba la creación de una línea de tranvía. La pareja de empresarios recalca que el tranvía existente, que atravesaba de norte a sur la ciudad y la comunicaba con Chapinero, tenía la falencia de que concentraba su servicio exclusivamente en el transporte de pasajeros, desaprovechando los beneficios de las vías férreas por cuanto en estas "Ios pasajeros son un tráfico relativamente secundario si se los compara con la carga" (González y Pereira, 1898, p. 3).

De tal forma que los promotores planteaban el tranvía de San Cristóbal como un medio de transporte de mercancía. Al mismo tiempo, González y Pereira contemplaban que las mercancías que podría cargar el tranvía eran "1. Piedra, 2. Materiales cocidos, 3. Arena, 4. Piedra de cal, 5. Trigo y harina, 6. Leña, 7. Rama, 8. Maderas diversas, 9. Víveres". En últimas, la hipotética carga del tranvía estaría compuesta por mercancías que podían producirse fácilmente en San Cristóbal. Por lo tanto, los promotores del tranvía buscaban ofrecer un medio de comunicación "fácil y barato", para quienes quisieran iniciar empresas en el suroriente (González y Pereira, 1898, pp. 9-10). ${ }^{3}$

3 Hay también quienes afirman que, al presentar al tranvía de San Cristóbal como un tranvía de carga, lo que querían Pereira y González era evitar conflictos con la ya establecida Bogotá City Railway Company, siguiendo de esta manera el ejemplo de un tranvía de carga en Zipaquirá (Pérgolis y Valenzuela, 2011, p. 27). Esta afirmación tiene más sentido si tenemos en cuenta que en su folleto, los promotores dejan muy claro que su tranvía ha de construirse sobre terrenos que en su totalidad son privados, propiedad de algunos capitalistas de la compañía, para así evitar problemas relacionados con la asignación de privilegios (González y Pereira, 1898, p. 7). 
La empresa, aunque compró algunos terrenos, ${ }^{4}$ no llevó a cabo el proyecto, y la compañía, fundada legalmente en una notaría bogotana en 1897, desapareció formalmente en 1912, pero lo cierto es que la urbanización de San Cristóbal ya no tenía marcha atrás. A los ojos de Pereira, el sur de Bogotá se desarrollaría como lugar de habitación de los capitalinos gracias a la construcción de "residencias de recreo", y como núcleo productivo que albergaría "fincas de explotación" (González y Pereira, 1898, p. 6).

Plano 2. Trazado del tranvía de San Cristóbal, 1911

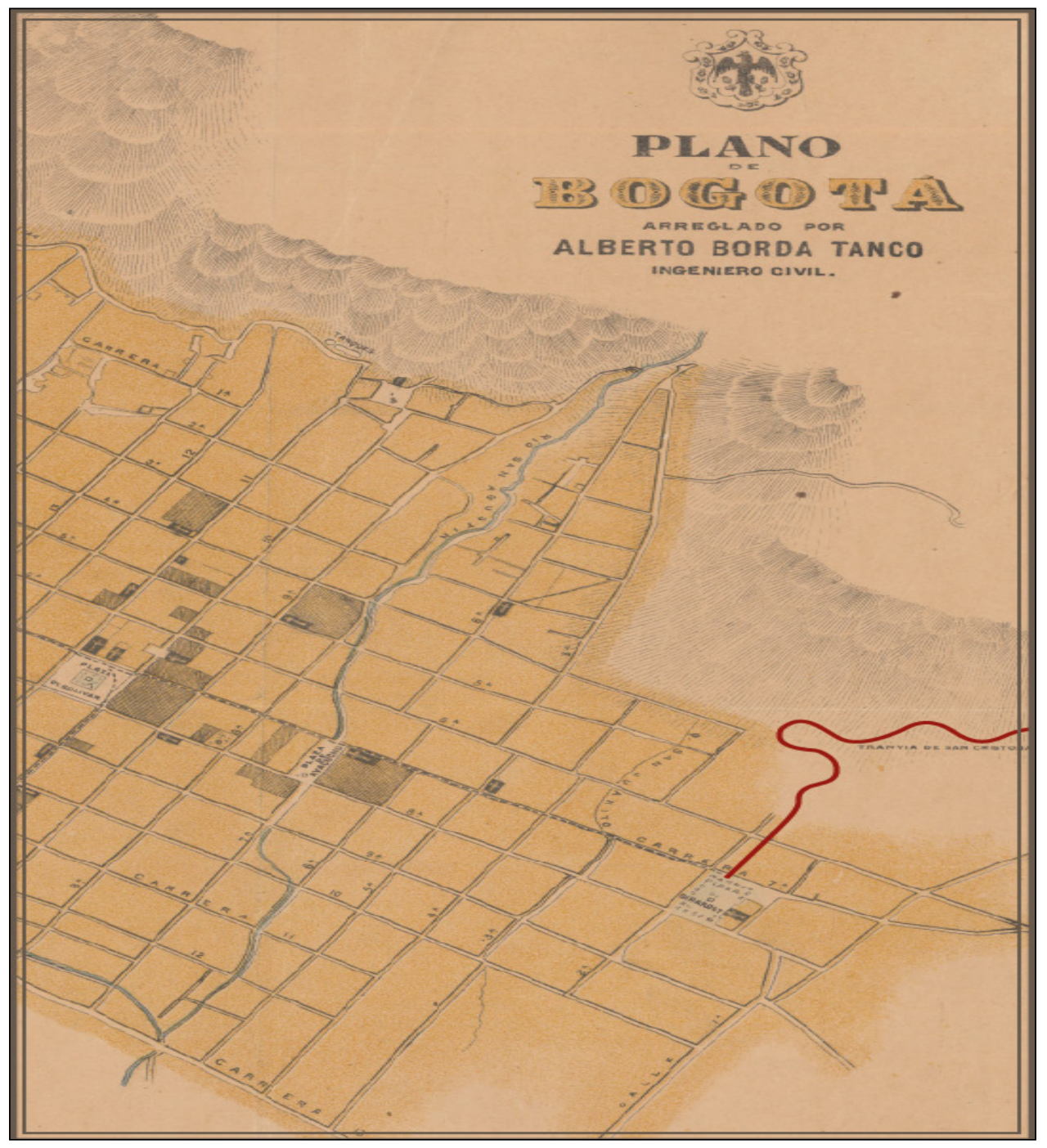

Detalle del plano de Bogotá por Alberto Borda Tanco realizado en 1911. El ingeniero Borda Tanco plasmó en su plano el trazado de la línea del tranvía proyectado por Pereira y González en 1898.

Fuente: Cuéllar y Mejía (2007, p. 65). En el original, la línea del proyectado tranvía a San Cristóbal aparece marcado con una línea punteada. Hemos resaltado la línea en rojo

4 Incluso para mediados de la década de 1900 algunas guías de la ciudad daban por hecho el funcionamiento del tranvía de San Cristóbal (Patiño, 1902) (Zamora, 1907). 


\section{La urbanización en San Cristóbal}

La historia de San Cristóbal en el siglo xx no se dio acorde a los vaticinios de sus primeros promotores, pues las fincas de recreo dieron paso a barrios de población trabajadora. Los chircales y la fabricación de ladrillo fueron determinantes en la urbanización, ya que en torno a esta actividad económica se aglomeraron pobladores que se afincaron en el suroriente. En 1898 el alcalde Higinio Cualla nos da un claro testimonio de este proceso. En un breve informe sobre la situación geográfica y política de la ciudad, Cualla trata la situación de los ríos de la ciudad, nos dice que "en toda la hoya del San Cristóbal y laterales [...] se encuentran innumerables chozas de labradores, de carboneros, etc." Muchos de estos habitantes eran atraídos por la actividad extractiva en yacimientos de "carbonato de cal de diversas clases [...] de carbón, muy abundantes piedras de labor para construcción, etc." (Cualla, 1898, pp. 4217-4218).

La cantidad de población ubicada en el suroriente era ya tan importante para principios del siglo xx, que, según Germán Mejía, en 1902 las autoridades municipales consideraron necesario asignar a San Cristóbal un comisario de policía dependiente de la inspección del barrio Las Cruces (Mejía, 2000, p. 332). Sobre la ribera norte del río Fucha se fue formando el barrio San Cristóbal, el cual, para 1913 contaba ya con un comisario de policía, y para 1917 el municipio había creado para el barrio su propia inspección de policía.

Pero el impulso urbanizador definitivo en la zona de San Cristóbal lo dieron los barrios obreros, los barrios construidos por empresarios privados, la iglesia católica y las autoridades municipales para la población trabajadora de la ciudad.

A principios del siglo xx la vivienda de los trabajadores se convirtió en un problema relevante para las autoridades municipales por la crisis sanitaria que alcanzó su clímax a finales de 1918, durante la epidemia de gripe española. La crisis sanitaria se achacó a las pobres condiciones de habitación de los sectores populares de la ciudad y al hacinamiento. Poco a poco, por la disponibilidad de tierras, de fuentes de agua potable y núcleos productivos, San Cristóbal fue identificándose como una zona propicia para la edificación de los nuevos barrios para la población trabajadora bogotana que demandaba soluciones de vivienda.

Ya desde mediados de la década de 1900 comenzaron a escucharse voces en favor de la construcción de un barrio para obreros en San Cristóbal que entrara a mitigar los problemas de hábitat de los obreros capitalinos. El ingeniero Alfredo Ortega propuso en 1909 que las nuevas viviendas para obreros que proyectara el municipio debían ubicarse en el suroriente, en "la región bañada por el río San Cristóbal", porque allí los habitantes obreros podrán conseguir empleo, ya que en ese lugar "se ha establecido un centro industrial en el cual hay varias fábricas de loza y algunos tejares. Existe además, una línea de tranvía, cuya Compañía puede hacer un arreglo equitativo con los obreros para transportarlos á la ciudad por la mañana y por la tarde, mediante una tarifa módica." (Ortega, 1909, p. 282).5

Entre las décadas de 1910 y 1920 varios médicos e ingenieros seguirían insistiendo en la idoneidad de San Cristóbal para la construcción de nuevos barrios obreros, ${ }^{6}$ pero fue la iglesia católica la que abrió el camino para la construcción de barrios obreros en el suroriente. El

5 La línea del tranvía de la que habla el autor es la vía planificada por los empresarios Pereira y González que nunca se construyó.

6 Véanse por ejemplo los trabajos de los médicos José Gaitán (1915) y Camilo Tavera (1922). 
sacerdote jesuita José María Campoamor impulsó en 1913 la construcción de un barrio nuevo en el punto conocido como "El Peñón del Aserrío", con el fin de mejorar las condiciones de vida de la población trabajadora y evitar así que los obreros capitalinos cayeran bajo la influencia de ideas impías, como el socialismo y comunismo.

Este barrio llegó a conocerse como Villa Javier. Sus casas inicialmente eran arrendadas a personas que podían cumplir con la obligación; estas personas, además, se veían obligadas a cumplir un estricto reglamento que contemplaba estrictos valores cristianos como la pobreza, la moralidad, la piedad, la vida en familia, la educación y el aseo. La idea de Campoamor era la de dotar a una parte de la población obrera de Bogotá de un barrio que no solamente tuviera las condiciones físicas óptimas para la habitación, sino que también permitiera cultivar en sus ocupantes sanas costumbres que los alejaran del pecado, para lo cual era ideal la vida en un ambiente rural. Por eso es comprensible que Campoamor viera en San Cristóbal un espacio único para localizar sus viviendas, pues era una zona conectada con la ciudad pero que aún mantenía apariencia de campo (Londoño y Saldarriaga, 1994, pp. 50-90).

Ya en la década de 1920, el municipio tomó la iniciativa urbanizadora en San Cristóbal. Después de la epidemia de gripe, el gobierno central obligó a los gobiernos municipales a intervenir en el tema del vivienda por medio de la Ley 48 de 1918. En el marco de esta legislación, Bogotá creó en 1919 la Junta de Habitaciones para Obreros. Esta institución debía promover la construcción de casas modernas para obreros, contribuyendo así a solucionar los problemas relacionados con el hacinamiento y el déficit de vivienda.

Esta institución promovió la construcción de dos barrios obreros en San Cristóbal, el 1º de Mayo y Buenos Aires. La Junta y el Concejo Municipal decidieron instalar en San Cristóbal los barrios para obreros inicialmente porque allí consiguieron unos terrenos a buen precio ofertados por Nemesio Camacho (Registro Municipal, 1922, p. 4873). A principios de 1923 comenzó a construirse el $1^{\circ}$ de Mayo, y ya para noviembre de ese año se habían entregado las primeras 20 casas. Este barrio se ubicaba en un terreno sobre la orilla norte del río Fucha.

Tan pronto comenzó a construirse el barrio, las autoridades municipales dispusieron la edificación de un puente sobre el río con el fin de extender el tranvía hasta el nuevo barrio, pues para principios de la década de 1920, este sistema de transporte llegaba hasta el barrio San Cristóbal, pasando por los predios conocidos como Santa Ana. El $1^{\circ}$ de Mayo se ubicaba muy cerca de la línea ya existente, y su ubicación claramente tuvo que ver con la cercanía del tranvía. Si bien -como han señalado varios autores- la construcción de barrios obreros tenía motivaciones higienistas (Noguera, 1998), las autoridades municipales pensaban efectivamente que las viviendas que construyeran serían albergadas por obreros y trabajadores. Por tanto, la solución de vivienda implementada por el gobierno debía pensar también en facilitar la vida de los trabajadores, ya fuera ubicando los barrios en zonas aledañas a lugares de trabajo, o en terrenos que contaran con un acceso fácil al centro de la ciudad, ${ }^{7}$ por lo que la presencia del tranvía en cercanías de las nuevas viviendas era de suma importancia.

7 Como lo demuestran algunos de los planteamientos frente al problema de la vivienda obrera de políticos e ingenieros ligados al Concejo Municipal (Ortega, 1909; Gaitán, 1915; Registro Municipal, 1933, pp. 258-259).

tiempo\&economía

Vol. 5 N. 2 - Julio - Diciembre del 2018 
La Junta de Habitaciones para Obreros tuvo muchos problemas, no ejerció a cabalidad sus funciones, e incluso recibió muchas críticas porque se consideraba que sus obras no justificaban los fondos destinados a esta institución, ${ }^{8}$ y en 1930 se disolvió. No obstante, San Cristóbal continuaría urbanizándose con barrios para obreros, gracias a la labor de empresarios privados que loteaban haciendas y vendían predios a personas que se encargaban luego de construir las nuevas viviendas por sus propios medios.

Así se construyeron barrios como el 20 de Julio, Santa Ana y San Blas. La labor de los urbanizadores era bastante limitada, como ya se dijo, se reducía a lotear el terreno urbanizable, por lo que dotar los nuevos barrios con redes de servicios no era prioridad de empresarios como Rubén Possin o Salomón Gutt. Por eso, el gobierno municipal, concentrado en solucionar los problemas de higiene asociados a la situación de la vivienda, en la década de 1920 intentó regular el accionar de los urbanizadores privados, exigiendo que en la construcción de nuevos barrios se garantizara el abastecimiento de agua potable y la presencia de alcantarillado. Si los nuevos barrios y las viviendas no cumplían estas condiciones, el municipio no emitía autorización para su construcción. ${ }^{9}$

8 En 1924 la Junta de Mejoras Públicas del barrio San Diego (La Perseverancia) ubicado al norte de la calle 28 en un terreno al oriente del carrera 7a, expresó su descontento por la decisión del Municipio de utilizar los recursos asignados al mejoramiento de la vivienda obrera en la construcción de un barrio, el $1^{\circ}$ de Mayo, en una zona donde el impacto entre la población obrera era mínimo. Los representantes de los habitantes del barrio San Diego hicieron una petición pública al Concejo para que mejor construyera un barrio en ese sector de la ciudad, porque consideraban que allí una obra de saneamiento aliviaría verdaderamente la vida de muchos "proletarios". La Junta de San Diego alegaba que allí se encontraba el más importante núcleo de obreros en la ciudad, "cerca de veinte mil habitantes" entre los obreros y sus familias, por concentrarse allí la mayor cantidad de fábricas de la ciudad, como Bavaria, Fenicia y Chocolates Chaves y algunos otros establecimientos que emplean obreros como el cementerio, el Ferrocarril del Norte y el Tranvía (El Tiempo, 1924, p. 10). El Círculo de Obreros del padre Campoamor, promotor de barrio obrero Villa Javier, también criticó la administración de los fondos para vivienda que hacía la Junta de Habitaciones. A finales de 1927 en el Boletín del Círculo de Obreros se afirmaba que con los recursos que había utilizado la Junta para construir 24 casas en el barrio $1^{\circ}$ de Mayo, se hubieran edificado 200 del estilo del barrio Villa Javier, aliviando el problema de los altos costos de los alquileres de vivienda (citado en Londoño y Saldarriaga, 1994, pp. 97-99).

9 Así se puede evidenciar tanto en los múltiples decretos municipales sobre la construcción de vivienda higiénica y la dotación de redes de alcantarillado a las nuevas urbanizaciones. El hito de esta normatividad es el Acuerdo 27 de 1919 , con el cual se organizó la Junta de Habitaciones para Obreros, institución que tenía como tarea solucionar el problema de la vivienda de la población trabajadora, incentivando la construcción de nuevos barrios dotados con casas que cumplían ciertos parámetros higiénicos. No obstante, la normatividad sobre construcción de nuevos barrios y casas se remonta a principios del siglo XX. El Acuerdo 10 de 1902 planteó desde parámetros mínimos sobre higiene (iluminación, ventilación y acueducto) para la construcción de vivienda nueva en la capital, hasta lineamientos que tendrían que seguir los nuevos barrios que se construyeran extra-radio, como el ancho de las calles, disposiciones sobre construcción de andenes, alcantarillado, alumbrado público y cañerías. Entre 1905 y 1914 el municipio publicó más disposiciones de este estilo. Esta normatividad se publicaba siempre en forma de Acuerdos Municipales en el Registro Municipal. Ahora bien, las licencias de construcción nos muestran el esfuerzo del Municipio por regular la edificación de nuevos barrios y viviendas en la capital. En primer lugar, estos documentos cuentan con la aprobación o la negativa de la alcaldía para realizar la obra proyectada. Cuando la alcaldía negaba los permisos explicaba las razones, entre las que se cuenta que los diseños adjuntados no cumplían con parámetros como los desagües o los espacios para ventilación. De otro lado, muchas licencias de construcción eran la petición de ciudadanos del permiso para reiniciar obras que habían sido suspendidas por orden de las autoridades municipales, entre otras razones, por no cumplir con los parámetros exigidos por el Municipio. Las inspecciones de policía de la ciudad eran las encargadas de supervisar las nuevas construcciones en la ciudad, para actuar ante las irregularidades. Estas observaciones se desprenden del estudio minucioso de las licencias de construcción emitidas para toda la ciudad disponible en Fondo Unidad Administrativa Especial de Rehabilitación Vial de Archivo de Bogotá entre los años 1920 y 1936. 
No obstante, esto no detuvo a los urbanizadores privados, como lo demuestra el caso del barrio 20 de Julio. El barrio fue loteado por Rubén Possin en terrenos de una vieja hacienda al sur del río Fucha propiedad de Irene Convers de Manrique. La venta de lotes en el barrio se inició en mayo de 1920 (El Tiempo, 1920, p. 5a), y se presentó una solicitud de aprobación del nuevo barrio ante las autoridades municipales en noviembre del mismo año (Registro Municipal, 1920, p. 4125). Sin embargo, las licencias de construcción aprobadas por la Alcaldía nos muestran que no fue sino hasta 1928 cuando el barrio fue aprobado oficialmente por el municipio, pero para ese momento ya muchas personas habían adquirido lotes y habían comenzado a construir sus viviendas (Licencias de Construcción, 1925-1926).

De tal forma que no sería acertado afirmar que el tranvía fuera definitorio en la urbanización de San Cristóbal promovida por empresarios privados, pues si ni siquiera era una prioridad el agua potable, mucho menos lo sería el transporte. Es por eso comprensible que los urbanizadores privados no plantearan como eje de su labor la extensión de la línea del tranvía. Pese a ello, tampoco podríamos negar que el tranvía tuvo cierto impacto en el proceso de urbanización del sur: el barrio Santa Ana, urbanizado por agentes privados, se conformó desde finales de la década de 1910 en torno a la vía que subía paralela al río Fucha hacia el barrio San Cristóbal; y en la década de 1930 la petición que la iglesia católica y vecinos de los barrios del sur cursaron ante el municipio para que el tranvía se extendiera hasta el barrio 20 de Julio, se materializó.

\section{El tranvía municipal en el desarrollo urbano de San Cristóbal}

Por todo lo dicho hasta ahora, no es posible establecer una relación causal entre la urbanización del suroriente y la expansión del tranvía durante las primeras décadas del siglo xx. Asimismo, no se puede desconocer que el tranvía, de una forma u otra, influyó en la urbanización de San Cristóbal.

Consideremos primero que cuando los empresarios González y Pereira intentaron convertir la urbanización de San Cristóbal en un negocio rentable, pretendieron acompañar su proyecto de la construcción paralela de un tranvía que hiciera más apetecibles los terrenos del suroriente. Sin embargo, los promotores -como ya lo vimos- no presentaron su tranvía como un medio de transporte para pasajeros, sino de mercancías que fuera aprovechado por aquellas personas que quisieran explotar los recursos de la zona. ${ }^{10}$

Pero el hecho es que el tranvía de González y Pereira nunca se materializó, mientras que la urbanización en San Cristóbal no se detuvo, aunque no tomó la forma que sus promotores deseaban. Para principios de la década de 1910 la construcción de un nuevo núcleo de viviendas sobre la parte alta del río Fucha avanzaba firmemente. Así que para cuando el tranvía llegó a la zona, en 1917, ya muchos dueños de tierras en San Cristóbal pensaban en subdividir sus tierras y vender lotes para urbanizar.

Ahora bien, en segundo lugar debemos considerar las características de la urbanización y del tranvía mismo para comprender mejor la relación entre este medio de transporte y el desarrollo de San Cristóbal. El crecimiento urbano que experimentó la ciudad a principios del

10 Aunque también hay que tener en cuenta, como ya ha sido señalado, que cuando González y Pereira presentaron su tranvía como un transporte de mercancías, lo hacían en parte para evitar que la empresa de tranvía ya existente considerara una competencia riesgosa al tranvía de San Cristóbal (Pérgolis y Valenzuela, 2011, p. 27).

tiempo\&economía

Vol. 5 N. 2 - Julio - Diciembre del 2018 
siglo XX no fue resultado de una política sistemática de planeación postulada por las autoridades municipales o nacionales. La expansión de la ciudad se dio de manera espontánea, es decir que la urbanización no fue resultado de un plan sistemático organizado por las autoridades municipales, y en este proceso el barrio, promovido por urbanizadores privados, se convirtió en la unidad de producción de la ciudad. El crecimiento se dio mediante la agregación de pequeños fragmentos de suelo urbanizado cercanos a las vías que los conectaban con el centro de la ciudad. Las quintas y las estancias aledañas a la ciudad jugaron un rol central en el este proceso, pues sus terrenos se fueron parcelando y así se incorporaron al uso urbano. Por lo tanto, siguiendo a Del Castillo, podemos afirmar que Bogotá era, a principios del siglo xx, una ciudad "desarticulada", en la medida en que su crecimiento va dejando espacios mientras se van agregando los nuevos terrenos (Del Castillo, 2003, pp. 82-83).

La labor de los urbanizadores privados se limitaba al loteo. La construcción de las viviendas recaía en los compradores de los lotes. Las edificaciones terminaban erigiéndose acorde a las capacidades de los habitantes, por lo que se presentaron muchos problemas a la hora de suplir de servicios urbanos a los nuevos barrios. Las autoridades gubernamentales tuvieron poca injerencia en este proceso, y aun cuando intentaron regular las nuevas urbanizaciones, los hechos nos demuestran que las medidas tomadas no fueron muy efectivas. En muchos casos no se construían alcantarillas, los ciudadanos construían sin permiso de la alcaldía, o lo hacían sin ceñirse a las condiciones impuestas por las instituciones encargadas de regular la construcción de nuevas viviendas y barrios. Pero aún peor, lo que los documentos del periodo nos demuestran es que en muchos casos los ciudadanos quedaron a merced de las arbitrariedades de los empresarios, pues las autoridades municipales no fueron eficientes imponiendo un control sobre la actividad urbanizadora. ${ }^{11}$

Así pues, si la presencia de redes de acueducto y alcantarillado no era decisiva a la hora de plantear una nueva urbanización, no es de esperarse que la existencia de una línea de tranvía fuera prerrequisito para la construcción de un nuevo barrio en la Bogotá de principios del siglo pasado. En otras palabras, para los urbanizadores del suroriente capitalino no era vital contar con una conexión de tranvía como incentivo para promover los nuevos barrios. Sin embargo, cuando el tranvía llegó a San Cristóbal, este medio de transporte terminó estimulando el crecimiento urbano de la zona, y favoreciendo la construcción de vivienda para obreros. Y esto sin contar que los mismos pobladores de San Cristóbal exigieron la construcción de una línea de tranvía hacia sus barrios.

El tranvía llegó a San Cristóbal luego de la municipalización de la empresa, ocurrida a partir de 1910. En 1915 se planteó por primera vez extender hacia el sur una línea, empero la Junta Administrativa de la empresa le explicó al Concejo que no se podía llevar el tranvía al sur sino hasta que se llevara a cabo una prolongación de la duplicación de las carrileras entre la Plaza de Bolívar y Las Cruces. Pero lo interesante de los sucesos de 1915 es que podemos ver que la idea de extender el tranvía hacia el suroriente no provenía exclusivamente del Concejo, sino que los vecinos de la zona comenzaban a exigir que se comunicara el barrio con el centro de

11 Ver, por ejemplo, las denuncias realizadas en 1926 por habitantes del barrio Santa Lucía contra el urbanizador, Salomón Gutt, por vender lotes en una zona sin acueducto y alcantarillado, infringiendo así la normatividad municipal. La respuesta gubernamental ante las denuncias fue que simplemente el municipio aun no podía intervenir en este conflicto, pues el predio estaba situado en una zona que aún se encontraba fuera del área urbana (Licencias de construcción, 1926, folio 10). 
la ciudad por medio del tranvía. El Concejo controvirtió el diagnóstico de la empresa porque consideraba que el costo de obra impediría atender prontamente "el clamor de los vecinos de San Cristóbal" que piden la extensión del tranvía hasta allí. Después de un largo debate se concluyó que terminado "el trabajo indicado, la Junta prolongará la línea sur hasta el sitio llamado Las Brisas de San Cristóbal" (Registro Municipal, 1915, p. 2196).

Hay que señalar, además, que la petición de los habitantes de San Cristóbal que tomó forma en el Concejo en 1915 tenía antecedentes por lo menos dos años antes. En 1913 hay noticias de que una carta de vecinos de San Cristóbal y Las Cruces llegó al Concejo pidiendo la ampliación del tranvía hacia el sur, pero no sería sino hasta dos años después que el Concejo le daría importancia a las peticiones (EI Tiempo, 1938, p. Catorce). Ya en 1916, se dio vía libre a la construcción de una línea que conectara la plaza de Las Cruces con el punto conocido como Brisas de San Cristóbal, y desde allí hasta el puente sobre el río Fucha. Esta obra se financiaría con el dinero conseguido con la venta de un lote propiedad de la empresa del tranvía (Registro Municipal, 1916, p. 2420).

La obra quedó legalizada mediante el Acuerdo 11 de 1916, el cual aprobó la venta del lote de la empresa para financiar el proyecto, y planteó el trazado de la nueva línea de la siguiente manera: "partiendo del sitio denominado Brisas de San Cristóbal, pasa al occidente del Asilo de locas (Aserrío) [en cercanías al barrio Villa Javier], y atraviesa de Occidente a Oriente el predio Santa Ana hasta terminar en el puente del río San Cristóbal" (Registro Municipal, 1916, p. 2443).

Las obras se llevaron a cabo con algunas dificultades entre 1916 y 1917, sobre todo por la negativa a vender predios por parte de algunos propietarios de terrenos sobre los que pasaba la línea. Pero estos inconvenientes fueron casos aislados, y por el contrario, muchos propietarios de San Cristóbal comprendieron que el tranvía podría mejorar la zona y valorizar los terrenos. En un informe del estado de la construcción entregado por la Junta de la empresa al Concejo en febrero de 1917, se puede leer que

se excavaron 318 metros cúbicos de arcillas y areniscos muy compactos, que hubo necesidad de disgregar por medio de explosivos; esta cantidad de excavación corresponde a igual número de metros cúbicos de terraplén construidos sobre la alcantarilla de Los Molinos. Sobre la citada quebrada se construyó en el mes de diciembre [de 1916], casi en su totalidad, por varios propietarios interesados en la prolongación, una alcantarilla ovoide de ladrillo y mezcla de cal (Registro Municipal, 1916, p. 2420).

Las obras permitieron que en 1918 llegara el tranvía al corazón del barrio San Cristóbal. Luego este se extendería hacia el Fucha para conectar a los barrios $1^{\circ}$ de Mayo y 20 de Julio con el corazón de la ciudad.

En 1934 el Concejo aprobó la prolongación de la línea del tranvía hasta la calle 27 Sur, pasando por los barrios $1^{\circ}$ de Mayo y 20 de Julio (Registro Municipal, 1934, pp. 34-35). La ampliación del tranvía hasta la plazuela del barrio 20 de Julio se realizó, en parte, gracias a la presión de los habitantes de los barrios del sur y a los buenos oficios del sacerdote salesiano Juan del Rizzo.

Existe evidencia que desde 1932 vecinos de los barrios del sur venían solicitando a las autoridades municipales la extensión del tranvía hacia las urbanizaciones ubicadas sobre 
la ribera sur del Fucha. Pero no fue sino hasta el año siguiente cuando el Concejo tomó en serio las solicitudes. En 1933 cursó en el Concejo una petición de los ciudadanos que vivían en el $1^{\circ}$ de Mayo y el 20 de Julio solicitando la ampliación de la línea del tranvía hacia sus lugares de residencia. En la sesión del 29 de agosto de ese año el Concejo discutió la petición, y aprobó comunicarle al gerente de la empresa del tranvía que esa corporación consideraba muy importante darle cumplimiento a la petición de los pobladores del suroriente (Registro Municipal, 1935, pp. 34-35).

En 1934 Juan del Rizzo logró que personajes de la ciudad como el fotógrafo y político liberal Sady González y el político liberal Aníbal Cardoso Gaitán, presionaran, con ayuda de la Asamblea general de los barrios del sur -una organización que agrupaba representantes de los barrios del sur pero de la que se dispone de poca información-, al Concejo Municipal para que autorizara la prolongación de este medio de transporte hasta el barrio. Lo que buscaba el sacerdote salesiano era impulsar el culto al Divino Niño, el cual tenía como sede una capilla que luego se convertiría en el templo del Divino Niño. ${ }^{12}$ El sacerdote italiano subvencionaba su labor evangelizadora entre los niños, hijos de obreros y artesanos, con la ofrenda de pan y chocolate que hacían los feligreses de su capilla (Comisión local para la recuperación de la memoria histórica, 2009, p. 40).

La ampliación hacia el 20 de Julio desató un acalorado debate entre los miembros del Concejo y la gerencia de la empresa del tranvía. En mayo de 1934 el Concejo citó al gerente del tranvía con el fin de discutir la posibilidad de ampliar la cobertura hacia el barrio 20 de Julio. La postura del Concejo era clara: era necesario extender una línea del tranvía hacia esta zona. No obstante, las directivas de la empresa tenían sus reservas. Inicialmente el gerente de la empresa municipal del tranvía se opuso a la obra, pues argumentaba que "la prolongación de las líneas del tranvía a barrios obreros implicaba un gasto bastante apreciable". Ante estos reparos, el concejal Felipe Lleras Camargo ${ }^{13}$ respondió que "obras como la prolongación de las líneas del tranvía se debían llevar a cabo aun cuando dieran pérdida, pues se trataba de servir a los ciudadanos que más necesitados se hallaban de mejorar su condición de vida". Y es que lograr esta mejoría era una obligación programática del liberalismo, pues según Lleras, solamente así se podría "evitar que a los obreros se les siguiera engañando con utopías comunistas como la del concejal González Julio" (Libro de actas originales del Concejo, 1933-1935, sin paginación). ${ }^{14}$

Estas discusiones hay que entenderlas en el marco de las transformaciones políticas que experimentaba Colombia en ese momento. El partido Liberal ascendió al poder en el año de 1930, luego de casi 50 años de dominio conservador. Los gobiernos de Olaya Herrera (19301934) y López Pumarejo (1934-1938) plantearon una serie de reformas necesarias para promover la modernización, pero que al mismo tiempo pretendían ganarse al naciente movimiento obrero. La agitación obrera había llevado a varios movimientos huelguistas en la década de

12 En la actualidad este templo congrega a miles de feligreses que acuden a pedir favores a la imagen del Divino Niño. Pero este culto apenas se iniciaba en la década de 1930. El sacerdote salesiano de origen italiano Juan del Rizzo llegó al país con el fin de evangelizar a la población obrera del país. Con este objetivo se instaló en el 20 de Julio a comienzos del decenio de 1930, y le encargó a un escultor capitalino una figura infantil de Jesús para traer a la ciudad la devoción al Divino Niño y facilitar su tarea en el suroriente de la ciudad.

13 Hermano de Carlos Lleras Camargo, Presidente de la República de 1958 a 1962. 
1920, y representaba un desafío a las fuerzas sociales y políticas tradicionales. Estaba organizado por las primeras agrupaciones de estirpe socialista inspiradas por la Revolución Rusa de 1917: el Partido Socialista Revolucionario (1927-1930), y luego el Partido Comunista de Colombia, fundado en 1930 (Medina, 1980).

En últimas podemos aseverar que el tranvía revistió cierta importancia como medio de transporte para los vecinos de la zona de San Cristóbal. El tranvía tenía una ruta especial para obreros, el cual tenía una tarifa preferencial y un servicio en horarios especiales -a las 5 de la mañana y a las 5 de la tarde- (Contreras y Vélez, 1985, p. 100). Este servicio se implementó en la década de 1920 en la línea de San Cristóbal. Y para la década de 1940, la ruta que cubría Paiba-20 de Julio era reconocida como la más populosa, por la que se pagaba 2 centavos, y los carros tenían sillas de mimbre. Aunque también a San Cristóbal llegaban carros más lujosos. La ruta Palermo-San Cristóbal costaba 5 centavos y tenía mejores asientos. ${ }^{15}$

Plano 3. El Tranvía Municipal de San Cristóbal, 1916-1934

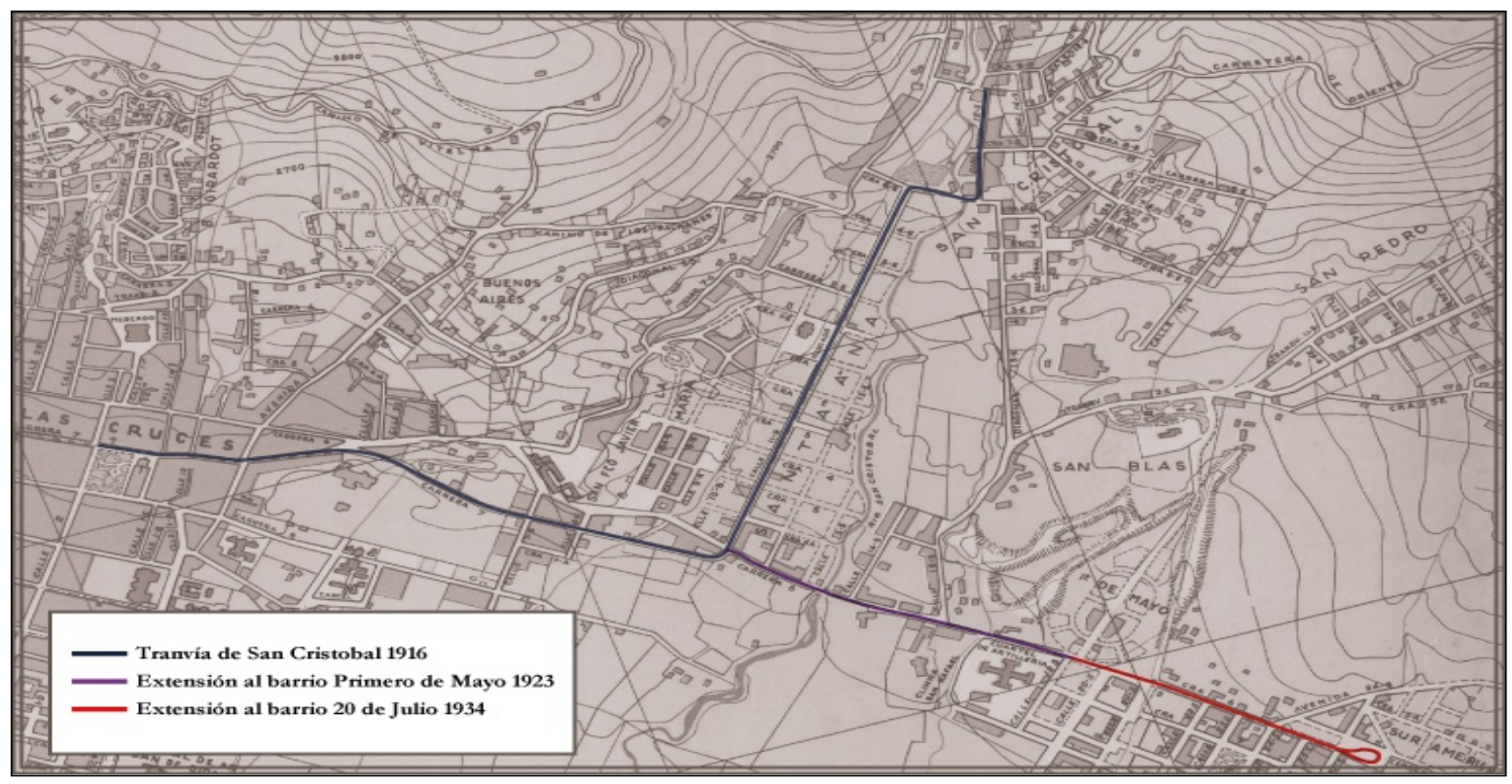

Detalle de la zona de San Cristóbal del plano de Bogotá de 1938 de la Secretaría de Obras Públicas Municipales con las líneas del Tranvía Municipal construidas entre 1916 y 1934 entre la plaza de Las Cruces y la plazoleta del templo del Divino Niño, en el barrio 20 de Julio.

Fuente: Cuéllar y Mejía (2007, p. 93). En el plano original la línea del tranvía aparece representada con una línea punteada. Las fechas de extensión del tranvía hacia el suroriente, marcadas con tres colores distintos, las hemos establecido con la documentación expuesta por el Concejo Municipal en el Registro Municipal entre 1916 y 1935, cuando se autorizaban nuevas obras

La obra finalmente se terminó en la segunda mitad de la década de 1930. El tranvía pasaba por un puente sobre el río Fucha, luego por frente a los terrenos del $1^{\circ}$ de Mayo y llegaba hasta la plazuela del barrio 20 de Julio, donde se ubicaba la iglesia, sobre la calle 27 Sur.

15 Testimonio de Lisandro Ramírez, habitante del barrio Santa Ana desde principios de la década de 1940 y obrero de "Textiles Sedazos" (citado en Aldana, 2008, pp. 43-44). 
Este medio de transporte favoreció el desplazamiento de los feligreses hacia el cada vez más popular templo del Divino Niño, facilitó un traslado más rápido de los habitantes de los barrios del suroriente -desde la década de 1940 fueron apareciendo más barrios aledaños al $1^{\circ}$ de Mayo y el 20 de Julio, como San Blas, Manrique, Sur América, etc.-, e incluso impulsó la expansión física de una icónica fábrica bogotana del periodo. Tubos Moore, fundada en 1906 en un lote sobre la calle 1 a, construyó una nueva planta en 1945 en un terreno contiguo al barrio 20 de Julio. Algunos de los trabajadores de esta nueva planta se vieron favorecidos por el tranvía.

\section{Consideraciones finales}

El tranvía de Bogotá ha despertado el interés de varios investigadores, los trabajos que hasta ahora se han producido se han concentrado en el estudio de la trayectoria general de este medio de transporte, develando su evolución de empresa privada a municipal, hasta su desaparición en la década de 1950. Otros trabajos han considerado el impacto general del tranvía en el crecimiento urbano bogotano. Sin embargo la relación entre la aparición de barrios extra-radio en la ciudad y las líneas del tranvía ha sido un tema poco menos trabajado. Tal vez se debe a la dispersión de las fuentes documentales, pues la empresa del tranvía ni siquiera cuenta con un fondo propio en el Archivo de Bogotá, y buena parte de la información debe buscarse en la documentación del Concejo Municipal.

El presente artículo ha explorado precisamente esta relación en el caso de los barrios aparecidos al suroriente de la ciudad en las primeras décadas del siglo xx. Lo que es claro es que no existe una relación causal entre el desarrollo urbano de San Cristóbal y el tranvía: aunque algunos promotores de la urbanización en el suroriente previeron que un medio de transporte como el tranvía impulsaría el desarrollo del sector, el tranvía no se convirtió en condición previa para la edificación de nuevos barrios.

De hecho lo que podemos observar es que el ensanche de la ciudad que se dio en la primera mitad del siglo xx no se acompañó de la construcción de infraestructura básica de servicios urbanos. Los empresarios privados, principal agente urbanizador, loteaban terrenos aledaños a la ciudad y así los articulaban al mercado de vivienda. Después, el gobierno municipal se encargaba de regular con normativa la construcción de los nuevos barrios y de dotarlos con servicios (Del Castillo, 2003, p. 80).

Pero, pese a lo anterior, no podemos tampoco desconocer que la presencia del tranvía en zonas de nueva urbanización como San Cristóbal fue considerada necesaria -por las autoridades municipales y por los ciudadanos- para promover la integración de los barrios de reciente construcción a la ciudad. Aunque la expansión urbana de Bogotá se adelantaba independientemente de la extensión de las redes de servicios urbanos hacia los nuevos barrios, lo que es evidente es que, en su momento, diversos actores sociales identificaron al tranvía como un servicio de suma importancia para la vida cotidiana, tal como lo expresa el caso de los barrios de San Cristóbal.

Los empresarios Fortunato Pereira y Máximo González, pioneros en la urbanización de San Cristóbal, entendieron que para hacer viable su proyecto necesitaban integrar los terrenos del suroriente al resto de la ciudad por medio del tranvía. Así, al mismo tiempo que promovían la 
construcción de un nuevo suburbio en esta zona, crearon su propia empresa del tranvía para San Cristóbal, que se mantuvo vigente hasta 1912. Aunque los proyectos de estos empresarios naufragaron, la urbanización de San Cristóbal siguió su curso. Pensada inicialmente como una zona de habitación para gentes acomodadas, San Cristóbal terminó albergando vivienda para obreros. Para la década de 1920, los habitantes de estos barrios exigieron la extensión del tranvía hacia sus viviendas, lo cual es muestra de que estas personas veían este medio de transporte como un servicio esencial para sus vidas. Aunque los barrios ubicados en San Cristóbal no se encontraban muy distantes del centro de la ciudad (a una distancia de máximo de $\left.2 \mathrm{~km}^{16}\right)$, para los habitantes de estos barrios reducir el tiempo de traslado de sus hogares al centro de la ciudad era importante, como lo demuestran tanto las peticiones populares que cursaron en el Concejo solicitando la extensión del tranvía al sur del río Fucha, como el hecho de que funcionaba en San Cristóbal una ruta especial para obreros, siendo una de las más concurridas.

Por su parte, las autoridades municipales desde finales de la década de 1910 fueron identificando al tranvía como un servicio esencial con el fin de mejorar las condiciones de vida de la población trabajadora de la ciudad. Específicamente en el suroriente, el Concejo vio necesario comunicar esta zona con el corazón de la ciudad mediante el tranvía, con el fin de facilitar la movilidad de los habitantes del barrio $1^{\circ}$ de Mayo, construido por iniciativa de la Junta de Habitaciones para Obreros. Para la década de 1930, las autoridades municipales comenzaron a plantear el tema del transporte en los barrios obreros de San Cristóbal como un problema social al que debía dársele una respuesta adecuada. Así lo demuestran los argumentos ya citados del concejal Lleras Camargo a favor de la extensión del tranvía hacia los barrios $1^{\circ}$ de Mayo y 20 de Julio. El tema de la cobertura del tranvía fue tratado con especial interés con relación a los barrios que por aquel momento se identificaban como obreros, y el Concejal en cuestión abanderó la extensión de este medio de transporte como una forma de mitigar las luchas sociales.

El tranvía permitió ampliar la urbanización hacia San Cristóbal, pues hizo más asequible el suroriente, conectándolo con la ciudad. En adelante, la cercanía de los terrenos urbanizables a este medio de transporte comenzó a jugar a favor de la construcción de nuevos barrios en el sector. Finalmente podemos aseverar que la relación entre la urbanización del extra-radio de la ciudad y los medios de transporte es inevitable, pues, siguiendo a Del Castillo (2003), la infraestructura de transportes es vital tanto para el planeamiento de ciudades modernas como para el desarrollo industrial.

\section{Referencias}

\section{Fuentes primarias}

Acuerdo 11 de 1916. (18 de mayo de 1916). Registro Municipal, p. 2443.

Acuerdo 20 de 1934. (15 de junio de 1934). Registro Municipal, pp. 34-35.

16 Según lo señalaba el Concejo Municipal en un cuadro que relacionaba los barrios extremos de la ciudad para el año de 1923 (Registro Municipal, 1923, pp. 5113-5120).

tiempo\&economía

Vol. 5 N. ${ }^{\circ} 2$ - Julio - Diciembre del 2018 
Archivo de Bogotá. Fondo Concejo Municipal. Libro de actas originales del Concejo, periodo 1933-1935. Sesión del 22 de mayo de 1934, sin paginación.

Archivo de Bogotá. Fondo Unidad Administrativa Especial de Rehabilitación Vial. Licencias de construcción. Cajas 604.1566.01/02/03, 1926.

Cualla, H. (abril de 1898). Datos aproximados para la formación de la geografía y la estadística del municipio de Bogotá. Registro Municipal, pp. 4217-4218.

El Tiempo. (1924). La necesidad del barrio obrero de San Diego, 17 de febrero de 1924, p. 10.

El Tiempo. (1920). Lotes en el 20 de Julio, 4 de junio de 1920, p. $5 a$.

El Tiempo. (1938). Hace 25 años. El Tiempo, 19 de mayo de 1938, p. Catorce.

Gaitán H., J. (1915). Higiene de barrios obreros. Tesis para doctorado en medicina y cirugía. Bogotá: Escuela Tipográfica Salesiana.

González, M. y Pereira G, F. (1898) Tranvía de San Cristóbal. Prospectos y escrituras. Bogotá: Papelería de Samper Matiz.

Ortega D., A. (1909). Barrio Obrero. Apuntaciones sobre ingeniería sanitaria, que se presenta á la consideración de la Junta Constructora de casa de para familias pobres, parte I. Anales de ingeniería. 16(193), pp. 43-53.

Pereira G., F. (1899). El eucaliptus. Anales de ingeniería. 11(132-133), 217-223.

Pereira G., F. (1919). La vida en los Andes colombianos. Quito: Imprenta El Progreso.

Registro Municipal, 15 de mayo de 1933.

Registro Municipal, 24 de abril de 1916.

Registro Municipal, 24 de abril de 1916.

Registro Municipal, 25 de septiembre de 1915.

Registro Municipal, 30 de noviembre de 1920.

Registro Municipal, 9 de diciembre de 1922.

Registro Municipal, 4 de mayo de 1923.

Registro Municipal, 31 de diciembre de 1935.

Tavera Z., C. (1922). Habitaciones obreras en Bogotá. Bogotá: Casa Editorial Minerva.

\section{Fuentes secundarias}

Aldana A., P. (2008). Santa Ana Sur. Una historia que continúa. Bogotá: Corporación del Río Fucha.

Baquero, M. (2009). El Tranvía Municipal de Bogotá冈. Desarrollo y transición al sistema de buses municipal 1884-1951. Tesis de grado. Universidad Nacional de Colombia. Sede Bogotá.

Buendía N., J. (1974). Biografía del Doctor Fortunato Pereira Gamba, fundador de la Academia Nariñense de Historia, en 1910. En Congreso Nacional de Historia. El séptimo congreso nacional de historia de Medellín (pp. 270-288). Medellín: Editorial Granamérica. 
Contreras, L. M. y Vélez, M. G. (1985). Historia del tranvía en Bogotá, 1882-1952. Tesis de grado. Universidad Nacional de Colombia Sede Bogotá.

Cuéllar Sánchez, M. C. y Mejía Pavony, G., (2007), Atlas histórico de Bogotá cartografía 17912007. Bogotá: Alcaldía Mayor de Bogotá.

Del Castillo, J. C. (2003). Bogotá, el tránsito a la ciudad moderna 1920-1950. Bogotá: Universidad Nacional de Colombia.

Esquivel, T. (1997). Economía y transporte urbano en Bogotá 1884-1930. Memoria y Sociedad, 2(4), 39-61.

Jaramillo, S. y Parias, A. (1995). Vida pasión y muerte del tranvía en Bogotá. Bogotá: Universidad de los Andes, Centro de Estudios sobre Desarrollo Económico.

Londoño B., R, y Saldarriaga R., A. (1994), La ciudad de Dios en Bogotá. Barrio Villa Javier. Bogotá: Fundación Social.

Martínez, C. (1983). Cuadernos Proa 4, Apostillas y reseñas. Bogotá: Ediciones Proa.

Medina, M. (1980). Historia del Partido Comunista de Colombia. Tomo I. Bogotá: Editorial Colombia Nueva, CEIS.

Mejía, G. (2000). Los años del cambio: historia urbana de Bogotá, 1820-1910. Bogotá: Centro Editorial Javeriano, ICANH.

Montezuma, R. (2008). La ciudad del tranvía 1880-1920. Bogotá: Editorial Universidad del Rosario y Fundación Ciudad Humana.

Noguera, C. E. (1998). La higiene como política. Barrios obreros y dispositivo higiénico: Bogotá y Medellín a comienzos del siglo XX. Anuario Colombiano de Historia Social y de la Cultura, 25, 188-215.

Núñez, S. y Rodríguez, L. E. (2003). Empresas públicas de transporte en Bogotá: siglo XX. Bogotá: Alcaldía Mayor de Bogotá.

Pérgolis, J. C. y Valenzuela, J. (2011). El libro de los buses de Bogotá. Bogotá: Universidad Católica y Universidad del Rosario.

Suárez M., A. (2006). La ciudad de los elegidos: crecimiento urbano, jerarquización social y poder político, Bogotá (1910-1950). Bogotá: Banco de la República.

Vargas, J. y Zambrano, F. (1988). Santa Fe y Bogotá: Evolución histórica y servicios públicos, 1600-1957. En H. Suárez (ed.), Bogotá 450 años: retos y realidades (pp. 11-92). Bogotá: Foro Nacional por Colombia, Instituto Francés de Estudios Andinos (IFEA). 